\title{
Development of NHT Type Cooperative Learning Model through Tutor to Improve the Mathematics Combinatoric Ability
}

\author{
Doni Andriyan Zunaiedy ${ }^{*}$, Edi Syahputra, Asmin Panjaitan \\ Post Graduate Program in Mathematics Education, State University of Medan, Indonesia \\ *Corresponding author: andriyan_doni@yahoo.com
}

Received November 28, 2018; Revised January 06, 2019; Accepted February 11, 2019

\begin{abstract}
This study aims to develop students 'mathematical combinatoric ability by using Nht type cooperative models, including (1) students' thinking processes on combinatoric abilities (2) Combinatoric abilities of students after Nht type cooperative learning and (3) levels of active student activity during the learning process. this is the class X-Multimedia2 SMK PAB 1 Helvetia as many as 30 students and the object of this research is the combinatoric ability of students. This study is a qualitative descriptive study. The instrument which used u consists of a combinatoric ability test, and an observation questionnaire of student learning activities. Data analysis uses the NHT (Numbered Head Together) model. Based on the data obtained data, the thinking process of students on combinatoric abilities after learning with cooperative models of NHT type is categorized into three categories, namely high, medium and low. (1) Students with high combinatoric abilities have conceptual thinking processes and are neat in completing combinatoric ability tests. Students with medium combinatoric abilities are having conceptual thinking processes but are less neat in completing combinatoric ability tests. Students with low combinatoric abilities in understanding problems using processes imperfect thinking, not concentrate and unable to use alternatives to answer and are not conceptual and neat. (2) Combinatoric abilities that are possessed by students of SMK PAB 1 Helvetia after Nht type cooperative learning are good. (3) The overall results of student's presentations which is used during the teaching learning activities are in the se ideal time tolerance interval.
\end{abstract}

Keywords: Combinatoric ability, cooperative of NHT type

Cite This Article: Doni Andriyan Zunaiedy, Edi Syahputra, and Asmin Panjaitan, "Development of NHT Type Cooperative Learning Model through Tutor to Improve the Mathematics Combinatoric Ability." American Journal of Educational Research, vol. 7, no. 2 (2019): 141-144. doi: 10.12691/education-7-2-4.

\section{Introduction}

Learning models are procedures, sequences, steps, and ways that are used by teachers use in achieving learning objectives so that the guidelines in the learning process become more systematic and accurate, this will also encourage optimal learning result.

Baroody [1] suggests five aspects of combinatoric ability, the five aspects. The first aspect is representation (representing), means making another form of idea or problem, for example from the form of a table is represented in the form of a diagram. Representation can help students to explain concepts or ideas, make it easier to get strategies for solving and flexibility in answering math problems. The second aspect, listening, the listening aspect is very important in the discussion. The ability to listen to topics that are being discussed will affect the ability of students to give opinions or comments. The third aspect, reading, the process of reading is a complex activity, because it involves aspects of remembering, understanding, comparing, analyzing, and organizing what is contained in the reading. By reading someone can understand ideas that have been put forward by others through writing, so that a mathematical scientific community is formed, so that each member can accept mathematical ideas.

Some relevant research results relevant to this study are as follows Haydon [2] in his research concluded :

"Using NHT strategies has an added benefit of improving students active participation, social skills, and cooperative skills while reducing disruptive behavior. Furthermore, oven without a behavioral incentive package, teacher can use the NHT strategy by itself and thereby improve student social and academic behavior in comparison with their typical teaching strategies."

According to Gultom and Syahputra [3] that mathematical combinatoric skills are taught with the Numbered Heads Together model that are combined inductively and deductively and this approach is better than students' mathematical communication.

According to [4] from the results of the problem and analysis of combinatorial thinking of students can be predicted that students generally do not understand the given problem. Students do not use the enumeration 
process in calculation. In addition, almost all students do not make mathematical models for the problem. Students always use the fastest formula to solve a given problem.

According to [5] combinatorial thinking in solving mathematical problems is able to increase and develop learning devices.

According to [6] increasing the ability of mathematical creative thinking and the self-confidence of students who obtain Learning Eliciting Activities Model (MEAs) are higher than the ability to think creatively mathematically and the confidence of students who get conventional learning (2) There is no interaction between learning and gender of students towards the improving of mathematical creative thinking skills and student self-confidence.

According to [7] improving Students' creative Mathematical Thinking Ability mathematically and Confidence through the Application activity of Eliciting Application Models (MEAs) from Student's Gender.

\section{Research Method}

This research is included in the type of development research that emphasizes in the development of the NHT (Numbered HeadsTogether) type Cooperative Learning Model with peer tutors. Development of Nht type cooperative learning models with peer tutors by using Research and Development methods.

The instruments in this research are the tests of mathematical combinatoric abilities in the relative frequency material and Opportunity Materials. Mathematical combinatoric tests are used to obtain data about mathematical combinatorics in the form of description questions.

This study involved one experimental group. The given treatment given to the experimental group was maths learning by using the Nht type cooperative learning model with peer tutors to see the improvement of students' combinatoric abilities.

\section{Result and Discussion}

\subsection{Results Description of the Model Development Phase}

The results of the development of the learning model of each activity at the steps of developing of the learning model that are developed the'se that are combinatoric-based learning model are:

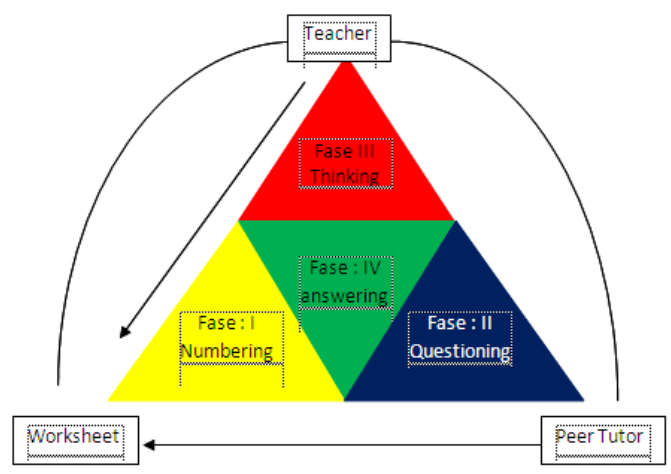

Figure 1. Learning Models

\subsection{Results of Student Mathematical Combinatoric Ability Data}

Data of students 'mathematical combinatoric abilities were obtained from students' mathematical combinatoric ability tests which were carried out twice that are the initial test (pretest) and the final test (posttest). The data of trial I results can be seen in the appendix. The general description of the results of the pretest of the mathematical combinatoric abilities of students of class X Multimedia-2 in the first trial is shown in the following table:

Table 1. Description of the Results of Mathematical Combinatoric Ability of Class X Multimedia-2 in SMK PAB 1

\begin{tabular}{|c|c|c|}
\hline Information & Pre-test & Pos-test \\
\hline The Highest Scor & 2,08 & 3,79 \\
\hline The Lowest Scor & 0,64 & 1,44 \\
\hline Average & 1,16 & 2,73 \\
\hline
\end{tabular}

For more details, see Figure 2 below:

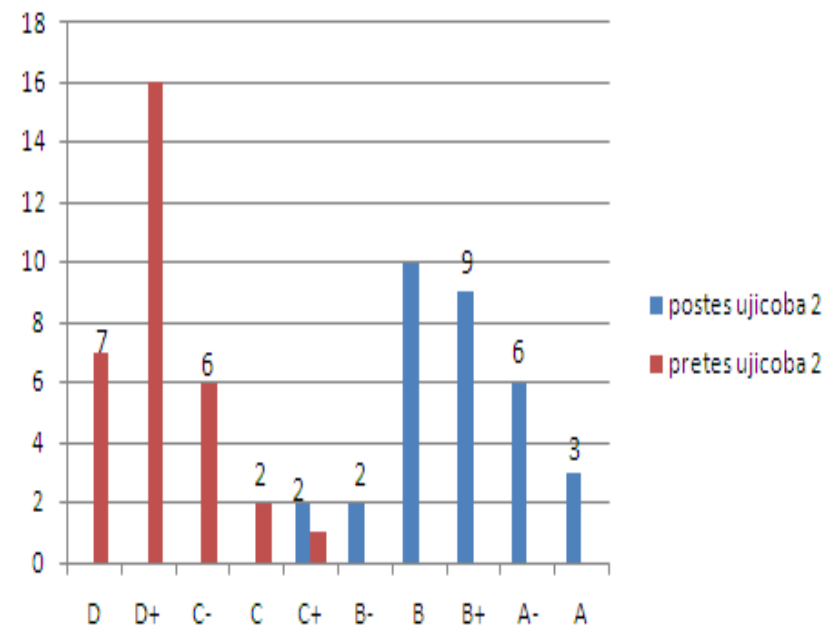

Figure 2. Value of Achievement of Multimedia-Class Student Mathematical Combinatoric Abilities in class X Multimedia at the Results of Pretest and Post-test

Based on the tables and pictures above, information was obtained that the posttest value of mathematical combinatoric abilities of students of class X Multimedia-2 for predicate A had an increasing in students' mathematical combinatoric abilities are compared to the results of pretest, from 0 to 3 people. Predicate A- there is an increasing in students 'mathematical combinatoric abilities, namely from 0 to 6 people, for the predicate $\mathrm{B}+$ there is an increasi in students' mathematical combinatoric abilities, from 0 to 9 people. Furthermore, for the predicate B, there was an increasing in students' mathematical combinatoric abilities are compared to the pretest score, namely from 0 to 10 students. Predicate B- there is a increasing mathematical combinatoric of students are compared to the pretest value, which is from 0 to 2 people. For the $\mathrm{C}+$ predicate there was an increasi in students' mathematical combinatoric abilities are compared to the pretest score, namely from 1 to 2 students. For the $\mathrm{C}$ predicate there was a decreasi in students' mathematical combinatoric abilities are compared to the pretest score, namely from 2 to 0 students. For the $\mathrm{C}$ - predicate, there was a decreasi in students' mathematical combinatoric abilities are 
compared to the pretest score, namely from 6 to 0 students. For the D + predicate there is a decreasi in the students 'mathematical combinatoric abilities are compared to the pretest score of 16 to 0 students, as well as the predicate D there is a decreasi in students' mathematical combinatoric ability are compared to the pretest score of 7 to 0 students.

The following is Figure 3 from the achievement of the pretest and posttest of the students' mathematical combinatoric abilities to the material of relative frequency and the oppurtunity material the chance of an event in the trial 2.

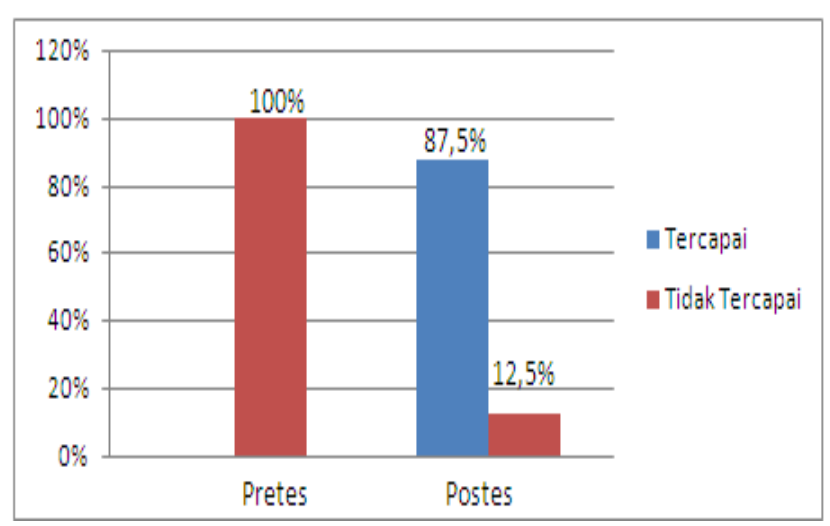

Figure 3. From the achievement of pretest and post-test of students' mathematical combinatoric abilities in the relative frequency material and opportunity materialin the second trial

Based on the explanation above, the number of students who have understood the mathematical combinatorics of students on the topic of relative frequency material and opportunity is 28 people $(87.50 \%)$ from 32 students who follow the posttest of students' mathematical combinatoric abilities. If this percentage is referred to the set out criteria set out in chapter III, it can be concluded that the percentage of students who are able to understand students' mathematical combinatorics has reached the set percentage.

The following is a Figure 4. of the achievement of the pretest and posttest of students' mathematical combinatoric abilities of the material of relative frequency and oppurtunity material in the trial I and II.

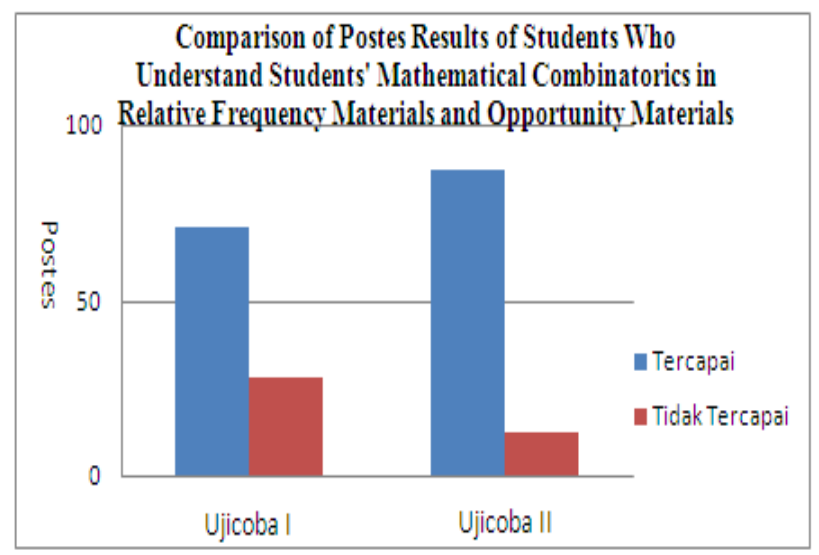

Figure 4. Comparison of Postes Results of Students Who Understand Mathematical Combinatorics of Students in Relative Frequency Materials and Opportunity Materials

Based on Table 1 and Figure 4 above, the percentage of students who have understood the mathematical combinatorics of students in the results of the first trial is $71.88 \%$ and in the second trial is $87.50 \%$. This shows that the percentage of students who have understood students' mathematical combinatorics in the material of relative frequency and the oppurtunity of an event has increased about $15.62 \%$.

The following is a condition of the average of mathematical combinatoric abilities of students in the study for each mathematical combinatoric aspect.

Table 2. Average of Each Aspect of Student Mathematical Combinatoric Ability in Trial II

\begin{tabular}{|l|c|c|c|}
\hline \multirow{2}{*}{$(1)$} & (2) & \multicolumn{2}{|c|}{ (3) } \\
\hline \multirow{2}{*}{$\begin{array}{l}\text { Mathematical } \\
\text { Combinatoric aspects }\end{array}$} & $\begin{array}{c}\text { No } \\
\text { Question }\end{array}$ & \multicolumn{2}{|c|}{ Mean } \\
\cline { 3 - 4 } & $1,2,3,4,5$ & 7,95 & 18,88 \\
\hline Drawing & $1,2,3,4,5$ & 7,66 & 19,29 \\
\hline Make a Models & $1,2,3,4,5$ & 8,15 & 19,10 \\
\hline Write & & 7,92 & 19,09 \\
\hline Overall Aspects & & & \\
\hline
\end{tabular}

The average of mathematical combinatoric ability in trial II can be illustrated in the following figure:

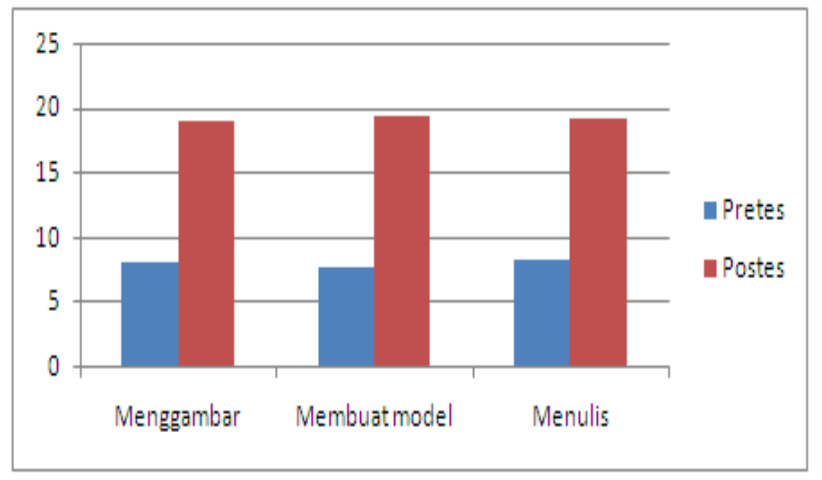

Figure 5. Average of Mathematical Combinatoric Capability Aspects in II

Figure 5 above from the average of mathematical trial combinatoric ability indicates that there is an increasing in each combinatoric aspect. Students get an increasing in mathematical combinatoric abilities on the drawing aspect with an average at pretest (7.95) while posttest (18.88), then on the aspect of making a model with an average pretest (7.66) while posttest (19.29) , and on aspects of writing with an average pretest (8.15) while posttest (19.10). It can be seen that from the average of mathematical combinatoric ability shows that there is an increasing in each combinatoric aspect.

\section{Conclusions}

Based on the results of the analysis and discussion in this research, several conclusions were presented as follows:

1. The level of achievement of students 'mathematical combinatoric abilities in the combinatoric based learning model is classically at $87.50 \%$ while the increasing in students' mathematical combinatoric abilities in the first trial is 2.73 increase to 3.05 in the trial II. 
2. Student responses to components in the combinatoric-based learning process has shown a positive response.

\section{Recommendation}

Based on the conclusions of the above research, the combinatoric learning which is applied provides important things to be notedas follows:

1. The learning model that is produced is only up to the development step, it has not been widely implemented at the schools. To find out the effective and valid problem combinatoric based learning model in various main subjects of discussion mathematical lessons and other appropriate subjects, it is recommended that teachers and researchers to implement the combinatoric-based learning model to be an alternative solution to this problem in the broader scope at the schools or in the education world.

2. The research instrument that is used to measure students' mathematical combinatoric abilities in the material of relative frequency and opportunity, but has not been able to measure the learning process that done by students to obtain overall learning outcomes, for that, this research can be combined with more in-depth research through qualitative research so student's learning can be obtained well.

3. Data of mathematical combinatoric ability on the material of relative frequency and opportunity using mathematical test instruments in the form of descriptions. The weakness of measurement with a description test is the limited number of tests, so that the scope of the material is only of a fundamental nature, it is feared that it has not been able to describe the mathematical combinatoric abilities of students as a whole. For teachers who want to apply the combinatoric based learning model to other subjects in mathematics or other subjects, they can design / develop the components of the learning approach and the characteristics of the learning model and the lesson material that will be developed.

\section{References}

[1] Qohar, Abd, "Pengembangan Instrumen Komunikasi Matematis Untuk Siswa SMP”. 2013.

[2] Haydon, T dkk, "Effect of Number Head Togetheron the Daily Quiz Scores and On-Task Behavior of Students with Disabilities," Journal of Behavioral Education, 19, 222-223. 2010.

[3] Gultom E.M. \& Syahputra E, “The Difference of Students’ Ability on MathematicsCommunication Through Numbered Heads Together Combined with Inductive Deductive Approach and Expository Method," Advances in Social Science, Education and Humanities Research, volume 104 2nd Annual International Seminar on Transformative Educational Leadership, 2017.

[4] Syahputra, E, "Combinatorial Thinking Analysis of Student Difficulties and Alternative Solution," The Third Annual International Seminar On Trends In Science and Science Education 7th-8th October, 2016.

[5] Ammamiarihta, Syahputra E. Surya E, "Development of Learning Devices Oriented Problem Based Learning to Increase Student's Combinatorial Thinking in Mathematical Problem Solving Ability,” Advances in Social Science, Education and Humanities Research, volume 104 2nd Annual International Seminar on Transformative Educational Leadership, 2017.

[6] Pane. N Syahputra. E Mulyono,” Improving the Ability of Creative Thinking Mathematically and Self-Confidence Student through Application Model Eliciting Activities (MEAs) Review from Student Gender," American Journal Of EducationAL Research, 6, 4, 319-323, 2018.

[7] Ritonga. E.M, Surya E, Syahputra E, “Development of Learning Devices Oriented Model Eliciting Activities to Improve Mathematical Problem Solving Ability Junior High School Students,” International Journal Of Sciences Basic and Applied Researcgh (IJSBAR) ISSN 2307-4531, 2017. 